\title{
Transthyretin-associated Familial Amyloid Polyneuropathy - Current and Emerging Therapies
}

\author{
Mario Nuvolone, ${ }^{1}$ Laura Obici ${ }^{2}$ and Giampaolo Merlini ${ }^{3}$
}

1. Postgraduate Researcher, Amyloidosis Research and Treatment Centre, Foundation IRCCS San Matteo Hospital and Department of Molecular Medicine, University of Pavia, Institute for Advanced Studies, Pavia and Institute of Neuropathology, University Hospital of Zürich; 2. Attending Physician and Researcher, Amyloidosis Research and Treatment Centre, Foundation Scientific Institute Policlinico, San Matteo; 3. Professor, Amyloidosis Research and Treatment Centre, Foundation IRCCS San Matteo Hospital and Department of Molecular Medicine, University of Pavia

\section{Abstract}

Transthyretin-associated familial amyloid polyneuropathy (TTR-FAP), the most common form of systemic hereditary amyloidosis worldwide, is a late-adult-onset autosomal dominant disease caused by mutations in the TTR gene, with peaks in prevalence in endemic areas. The clinical picture is dominated by a progressive length-dependent polyneuropathy with onset in the feet with loss of temperature and pain sensations, accompanied by life-threatening autonomic dysfunction and infiltrative cardiomyopathy, as well as ocular disturbances. Variable expressivity, in terms of age of onset and involvement of extra-neurological sites, can be due to different mutations, but is also observed among individuals with the same mutation in different countries. Therefore diagnosis of TTR-FAP is often a challenge and must rely on careful clinical assessment combined with a multidisciplinary approach. Elimination of the synthesis of mutated TTR, through liver transplantation, may arrest the progressive neuropathy but not the cardiac and ocular involvement. Novel drugs have recently been developed based on a better understanding of the molecular mechanisms of the disease. Drugs that prevent the misfolding and deposition of mutated TTR have entered clinical trials, and one of these, tafamidis meglumine, has been approved in Europe and is now clinically available. Other medicines are now in the pipeline aimed at suppressing the expression of the mutated TTR gene or at promoting amyloid fibril destructuration, favouring resorption of amyloid deposits. These recent advancements provide grounded hope of an imminent significant improvement in the care of this life-threatening multi-system disease.
\end{abstract}

\section{Keywords}

Amyloidosis, familial amyloid polyneuropathy, transthyretin amyloidosis, hereditary neuropathy, peripheral neuropathy

Disclosure: Mario Nuvolone received a travel grant from Pfizer. Laura Obici received consultancy honoraria from Pfizer. Giampaolo Merlini received speaker honoraria from Pfizer.

Acknowledgements: This work was supported by the Ricerca Finalizzata Malattie Rare, Italian Ministry of Health, Istituto Superiore di Sanità (526D/63), Ministry of Research and University (2007AESFX2-003), and Italian Association for Cancer Research Special Program Molecular Clinical Oncology (grant 9965). Mario Nuvolone is partially supported by an investigator fellowship of Collegio Ghislieri, Pavia. We are indebted to Dr Merrill Benson for generously sharing the table of the transthyretin mutations.

Received: 12 March 2012 Accepted: 30 March 2012 Citation: European Neurological Review, 2012;7(1):14-21 DOI:10.17925/ENR.2012.07.01.14 Correspondence: Giampaolo Merlini, Amyloidosis Research and Treatment Centre, Foundation IRCCS San Matteo Hospital and Department of Molecular Medicine, University of Pavia, Piazzale Golgi 2, 27100 Pavia, Italy. E: gmerlini@unipv.it

Amyloidoses encompass a heterogeneous group of disorders characterised by the accumulation and extracellular deposition of insoluble aggregates of misfolded fibrillar proteins termed amyloid, which can lead to tissue damage and organ dysfunction. ${ }^{1}$ They can be exceptionally rare or rather frequent, acquired or hereditary, localised or systemic, quite indolent or life-threatening. Amyloidoses are classified based on the main protein forming the deposits and include, as of today, 28 different forms. ${ }^{2,3}$

Transthyretin (TTR) amyloidoses (ATTR) retain much of the complexity of this family of maladies. Age-related deposition of wild-type TTR causes senile cardiac or systemic amyloidosis (SCA or SSA), ${ }^{4}$ affecting up to $25 \%$ of ultra-octogenarian people, ${ }^{5}$ whereas mutations in the TTR gene can result in hereditary forms of the disease, ${ }^{6}$ characterised either by a predominant neurological phenotype, also known as familial amyloid polyneuropathy (FAP), by a unique cardiac disease or by a mixture of the two. Several mutations are exceedingly rare and have been described only in single individuals or in single kindreds, whereas others are highly prevalent in certain geographical regions or among certain ethnic groups (such as the val122lle mutation, which can lead to isolated heart involvement and is carried by up to $4 \%$ of African-Americans). ${ }^{8}$ In addition, TTR-derived amyloid deposits can be focal (in the ligaments and tendons of aged individuals) ${ }^{9,10}$ or can be widespread in systemic forms of ATTR.

Here we will review the pathophysiological and clinical characteristics of TTR-associated familial amyloid polyneuropathy (TTR-FAP), with a focus on current and prospective treatments. 


\section{Transthyretin - Intrinsic Instability and Pathogenic Mutations}

Transthyretin, formerly termed prealbumin for its electrophoretic migration pattern, is a secreted polypeptide chain consisting of 127 amino acid residues ${ }^{11}$ with an approximate mass of $14 \mathrm{kDa}$ and a prominent $\beta$-sheet secondary structure. ${ }^{12}$ Four monomers associate non-covalently to form a tetramer which can bind thyroxine and holo-retinol-binding protein and circulates in the blood and in cerebrospinal fluid. However, the majority of circulating TTR is not bound. Virtually all TTR in plasma is of hepatic origin, but extrahepatic sites of TTR secretion include the choroid plexus and retinal pigment epithelium. Under physiological conditions, TRR reaches a plasma concentration of $0.2-0.4 \mathrm{~g} / \mathrm{l}$ and has a half-life of approximately $1-2$ days. ${ }^{7.13}$

Mutations in the TTR gene can be associated with hereditary forms of ATTR that are transmitted as an autosomal-dominant trait (see Table 1). Based on in vitro studies, disease-associated mutations have been shown to reduce the thermodynamic stability of TTR tetramers, favouring their dissociation into monomers, which can undergo unfolding, self-aggregation and amyloid formation. . $7,74,15^{1}$ This concept has been corroborated by observations made on a non-pathogenic variant of TTR, Thr119Met, which confers a stabilising effect on TTR tetramers in association with both the wild-type and the amyloidogenic Val30Met variant of TTR. ${ }^{16,17}$ Remarkably, compound heterozygotes for Thr119Met and Val30Met variants of TTR display a more benign evolution of the TTR-FAP associated with the Val30Met mutation. ${ }^{16}$

A certain degree of instability is an intrinsic feature of TTR, since even wild-type TTR can form amyloid deposits during ageing. ${ }^{4}$ Such inherent amyloidogenic propensity of TTR is further enhanced in the presence of a disease-related variant of the protein. In affected individuals heterozygous for one of the pathogenic mutations, both normal and variant TTR are found within the deposits ${ }^{18-21}$ and this could explain why amyloid deposits can progress in patients for whom liver transplantation has almost eradicated the mutant TTR circulating in the blood. ${ }^{18-20}$

C-terminal fragments of TTR are found in the deposits in addition to full-length TTR molecules in some cases. ${ }^{22-24}$ The enzyme responsible for this remains to be identified and it is currently unknown whether proteolysis of TTR precedes or follows amyloid formation. ${ }^{1}$ Also, TTR fibrillogenesis and deposition are believed to be influenced by the interaction with glycosaminoglycans and the serum amyloid $\mathrm{P}$ component (SAP), which are common constituents of all types of amyloid deposits.

\section{Transthyretin-related Familial Amyloid Polyneuropathy}

\section{Epidemiology and Genetics}

FAP associated with mutations of TTR is the most common form of hereditary ATTR and of hereditary amyloidoses in general. ${ }^{25}$ First reported in 1952 by Andrade in Portugal, ${ }^{26}$ it was subsequently described in Japan $^{27}$ and Sweden ${ }^{28}$ and it is now believed to occur worldwide. At present, 113 different mutations in the TTR gene have been associated with amyloid formation (see Table 1). Among these, the most common pathogenic mutation by far is Val30Met, which is responsible for the presence of endemic foci of TTR-FAP in northern Portugal, ${ }^{29}$ northern Sweden, ${ }^{28}$ Japan $^{30}$ and the Balearic Islands, ${ }^{31}$ but has also been reported elsewhere. For some mutations there is a strong genotype-phenotype correlation, whereas other variants show higher degrees of phenotypic variation. ${ }^{7,32,33}$ For example, the Val30Met mutation has a later clinical onset (at 55-60 years of age on average) and a lower penetrance (69\% at 90 years) in northern Sweden $^{34}$ and an earlier clinical manifestation (at 30-35 years of age) and a much higher penetrance (89\% at 60 years and $91 \%$ at 80 years) in Portugal. ${ }^{35}$ The gender of the transmitting parent was shown to impact the penetrance of the disease. ${ }^{34,36}$ Genetic anticipation has been described in several kindreds in endemic areas. ${ }^{37-39}$ The genetic factors underlying these phenomena are currently unknown but are under intense scrutiny. ${ }^{40-44}$ Moreover, anecdotal reports of discordant cases of TTR-FAP in monozygotic twins ${ }^{45-49}$ suggest the involvement of presently unidentified environmental factors.

\section{Clinical Features}

The clinical picture of TTR-FAP is dominated by the association of a sensorimotor and autonomic polyneuropathy with a family history of neuropathy. ${ }^{7.50,51}$ The clinical onset is characterised by numbness and spontaneous pains in the feet, impaired thermal sensitivity over the feet and reduced pinprick sensation with preserved light touch sensation and proprioception. The hallmark is the relentless proximal progression of the sensory deficits, which, during the following months and years, extend to the thighs and to the upper limbs. As larger sensory and motor nerve fibres become involved, impairment of light touch and deep sensations, with motor deficits, ensues. These manifestations are often accompanied or preceded by carpal tunnel syndrome. Unassisted walking becomes progressively difficult and autonomic dysfunction emerges with cardiocirculatory, gastrointestinal and genitourinary dysfunctions including orthostatic hypotension, severe constipation/episodic postprandial diarrhoea or alternation thereof, dysuria, urinary retention and erectile dysfunction in men. ${ }^{7.50,51}$ The latter can often be the first manifestation of the disease.

Differences have been reported in presentation between early-onset cases in endemic areas and late-onset cases in non-endemic areas (reviewed by Plante-Bordeneuve and Said). ${ }^{51}$ In the latter cases there is a preponderance of males, milder autonomic dysfunction and more frequent heart involvement.

Involvement of the ciliary nerve may lead to the so-called 'scalloped pupils', which are almost pathognomonic for FAP ${ }^{26,52}$ and involvement of the recurrent laryngeal nerve can cause vocal hoarseness.

Central nervous system (CNS) manifestations - including recurrent cerebral haemorrhage, seizures, psychosis, deafness and visual impairment - are present in association with some TTR mutations and, when they dominate the clinical picture, they are indicated as TTR-associated leptomeningeal or oculoleptomeningeal amyloidosis or cerebral amyloid angiopathy. ${ }^{53-56}$

Non-neurological manifestations can arise as a result of TTR amyloid deposition in the heart, eyes and kidneys. Progressive amyloid deposition within the heart induces electrical disturbances and restrictive cardiomyopathy with distinctive features with respect to other types of amyloid cardiomyopathy and which is often the cause of death in TTR-FAP patients. ${ }^{57-59}$ When, in association with specific mutations, the cardiac involvement dominates the clinical picture, the disease is rather referred to as familial amyloid cardiomyopathy (FAC). ${ }^{8,60}$ Ocular manifestations comprise abnormal conjunctival vessels, keratoconjunctivitis sicca, vitreous opacity and glaucoma. ${ }^{61}$ 
Table 1: Transthyretin Mutations Associated with Amyloidosis

\begin{tabular}{|c|c|c|c|c|c|c|c|}
\hline Mutation & $\begin{array}{l}\text { Codon } \\
\text { Change }\end{array}$ & $\begin{array}{l}\text { Clinical } \\
\text { Features }\end{array}$ & $\begin{array}{l}\text { Geographical } \\
\text { Kindreds }\end{array}$ & Mutation & $\begin{array}{l}\text { Codon } \\
\text { Change }\end{array}$ & $\begin{array}{l}\text { Clinical } \\
\text { Features }\end{array}$ & $\begin{array}{l}\text { Geographical } \\
\text { Kindreds }\end{array}$ \\
\hline Cys10Arg & TGT - CGT & Heart, eye ${ }^{* *}, \mathrm{PN}$ & US (PA) & Leu55Pro & CTG - CCG & Heart, AN, eye & US, Taiwan \\
\hline Leu12Pro & CTG - CCG & LM & UK & Leu55Arg & $-\mathrm{CGG}$ & LM & Germany \\
\hline Asp18Glu & GAT - GAA & PN & South America, US & Leu55GIn & $-\mathrm{CAG}$ & Eye, PN & US \\
\hline Asp18Gly & - GGT & LM & Hungary & Leu55Glu & $-\mathrm{CAG}$ & Heart, PN, AN & Sweden \\
\hline Asp18Asn & - AAT & Heart & US & His56Arg & CAT - CGT & Heart & US \\
\hline Val20Ile & GTC - ATC & Heart, CTS & Germany, US & Gly57Arg & GGG - AGG & Heart & Sweden \\
\hline Ser23Asn & AGT - AAT & Heart, PN & US & Leu58His & CTC - CAC & CTS, heart & US (MD) (FAP II) \\
\hline Pro24Ser & CCT - TCT & Heart, CTS, PN & US & Leu58Arg & $-\mathrm{CGC}$ & CTS, AN, eye & Japan \\
\hline Ala25Ser & $\mathrm{GCC}-\mathrm{TCC}$ & Heart, CTS, PN & US & Thr59Lys & ACA - AAA & Heart, PN, AN & Italy, US (Chinese) \\
\hline Ala25Thr & $-\mathrm{ACC}$ & LM, PN & Japan & Thr60Ala & ACT - GCT & Heart, CTS & US (Appalachian) \\
\hline Val28Met & GTG - ATG & PN, AN & Portugal & Glu61Lys & GAG - AAG & PN & Japan \\
\hline Val30Met & - ATG & PN, AN, eye, LM & $\begin{array}{l}\text { Portugal, Japan, } \\
\text { Sweden, US (FAP I) }\end{array}$ & Glu61Gly & $-\mathrm{GGG}$ & Heart, PN & US \\
\hline Val30Ala & $-G C G$ & Heart, AN & US & Glu62Lys & $-A A G$ & PN & Italy \\
\hline Val30Leu & - CTG & PN, heart & Japan & Phe64Leu & TTT - CTT/TTG & PN, CTS, heart & US, Italy \\
\hline Val30Gly & $-G G G$ & LM, eye & US & Phe64lle & - ATT & & \\
\hline Val32Ala & $-G C G$ & PN & Israel & Phe64Ser & $-\mathrm{TCT}$ & LM, PN, eye & Canada, UK \\
\hline Val32Gly & $-G G G$ & PN, AN & France & Gly67Glu & GGG - GAG & & \\
\hline Phe33lle & TTC - ATC & PN, eye & Israel & Ile68Leu & ATA - TTA & Heart & Germany \\
\hline Phe33Leu & - CTC & PN, heart & US & Tyr69His & TAC - CAC & Eye, LM & Canada, US, Sweden \\
\hline Phe33Val & - GTC & PN & UK, Japan, China & Tyr69lle & $-\mathrm{ATC}^{\star}$ & Heart, CTS, AN & Japan \\
\hline Phe33Cys & $-\mathrm{TGC}$ & CTS, heart, eye, kidney & US & Lys70Asn & $A A A-A A C$ & Eye, CTS, PN & US \\
\hline Arg34Ser & $A G A-A G C / T$ & PN, heart & US & Val71Ala & GTG - GCG & PN, eye, CTS & France, Spain \\
\hline Arg34Thr & $-\mathrm{ACA}$ & PN, heart & Italy & Ile73Val & ATA - GTA & PN, AN & Bangladesh \\
\hline Arg34Gly & - GGA & Eye & UK & Tyr75lle & ACC - ATC & Heart & France \\
\hline Lys35Asn & $A A G-A A C$ & PN, AN, heart & France & Ser77Tyr & TCT - TAT & Kidney & US (IL, TX), France \\
\hline Lys35Thr & $-\mathrm{ACG}$ & Eye & US & Ser77Phe & $-\mathrm{TTT}$ & PN, AN, heart & France \\
\hline Ala36Pro & $\mathrm{GCT}-\mathrm{CCT}$ & Eye, cTs & US & Tyr78Phe & TAC - TTC & PN, CTS, skin & France \\
\hline Asp38Ala & GAT - GCT & PN, heart & Japan & Ala81Thr & GCA - ACA & Heart & US \\
\hline Asp38Val & $-\mathrm{GTT}$ & PN, heart & Guiana & Ala81Val & - GTA & Heart & UK \\
\hline Asp39Val & GAC - GTC & Heart & Germany & Ile84Ser & ATC - AGC & Heart, CTS, eye & US (IN), Hungary (FAP II) \\
\hline Trp41Leu & TGG - TTG & Eye, PN & US & Ile84Asn & $-A A C$ & Heart, eye & US \\
\hline Glu42Gly & $\mathrm{GAG}-\mathrm{GGG}$ & PN, AN, heart & Japan, US, Russia & Ile84Thr & $-\mathrm{ACC}$ & Heart, PN & Germany, UK \\
\hline Glu42Asp & - GAT & Heart & France & His88Arg & CAT - CGT & Heart & Sweden \\
\hline Phe44Ser & TTT - TCT & PN, AN, heart & US & Glu89GIn & $\mathrm{GAG}-\mathrm{CAG}$ & PN, heart & Italy \\
\hline Phe44Tyr & - TAT & PN, AN & France & Glu89Lys & $-\mathrm{AAG}$ & PN, heart & US \\
\hline Ala45Thr & $\mathrm{GCC}-\mathrm{ACC}$ & Heart & US & His90Asp & CAT - GAT & Heart & UK \\
\hline Ala45Asp & $-\mathrm{GAC}$ & Heart, PN & US & Ala91Ser & GCA - TCA & PN, CTS, heart & France \\
\hline Ala45Ser & $-\mathrm{TCC}$ & Heart & Sweden & Glu92Lys & $\mathrm{GAG}-\mathrm{AAG}$ & Heart & Japan \\
\hline Gly47Arg & $\mathrm{GGG}-\mathrm{CGG} / \mathrm{AGG}$ & PN, AN & Japan & Val93Met & GTG - ATG & & Africa (France) Mali \\
\hline Gly47Ala & $-\mathrm{GCG}$ & Heart, AN & Italy, France & Val94Ala & GTA - GCA & Heart, PN, AN, kic & y Germany, US \\
\hline Gly47Val & - GTG & CTS, PN, AN, heart & Sri Lanka & Ala97Gly & $\mathrm{GCC}-\mathrm{GGC}$ & Heart, PN & Japan \\
\hline Gly47Glu & $-\mathrm{GAG}$ & Heart, PN, AN & Turkey, US, Germany & Ala97Ser & $-\mathrm{TCC}$ & PN, heart & Taiwan, US \\
\hline Thr49Ala & $\mathrm{ACC}-\mathrm{GCC}$ & Heart, CTS & France, Italy & Arg103Ser & $\mathrm{GGC}-\mathrm{AGC}$ & Heart & US \\
\hline Thr49lle & - ATC & PN, heart & Japan, Spain & Ile107Val & ATT - GTT & Heart, CTS, PN & US \\
\hline Thr49Pro & $-\mathrm{CCC}$ & Heart, PN & US & Ile107Met & - ATG & PN, heart & Germany \\
\hline Thr49Ser & $-A G C$ & PN & Indian & Ile107Phe & $-\mathrm{TTT}$ & PN, AN & UK \\
\hline Ser50Arg & AGT - AGG & AN, PN & $\begin{array}{l}\text { Japan, France/ } \\
\text { Italy, US }\end{array}$ & Ala109Ser & GCC - TCC & PN, AN & Japan \\
\hline Ser50lle & - ATT & Heart, PN, AN & Japan & Leu111Met & CTG - ATG & Heart & Denmark \\
\hline Glu51Gly & GAG - GGG & Heart & US & Ser112\|le & AGC - ATC & PN, heart & Italy \\
\hline Ser52Pro & TCT - CCT & PN, AN, heart, kidney & UK & Tyr114Cys & TAC - TGC & PN, AN, eye, LM & Japan, US \\
\hline Gly53Glu & GGA - GAA & LM, heart & Basque, Sweden & Tyr114His & - CAC & CTS, skin & Japan \\
\hline Gly53Ala & - ALA & LM & UK & Tyr116Ser & TAT - TCT & PN, CTS, AN & France \\
\hline Gly53Arg & $-A G A$ & LM & US & Ala120Ser & $\mathrm{GCT}-\mathrm{TCT}$ & Heart & Afro-Caribbean \\
\hline Glu54Gly & GAG - GGG & PN, AN, eye & UK & Ala120Thr & $-\mathrm{ACT}$ & PN, CTS & Japan \\
\hline Glu54Lys & $-A A G$ & PN, AN, heart, eye & Japan & Val122Ile & GTC - ATC & Heart & US \\
\hline \multirow[t]{2}{*}{ Glu54Leu } & - CTG & Heart & Belgium & $\Delta$ Val122 & $-\Delta \Delta \Delta$ & Heart, PN & US (Ecuador), Spain \\
\hline & & & & Val122Ala & $-\mathrm{GCC}$ & Heart, eye, PN & US \\
\hline
\end{tabular}

* Double nucleotide substitution. ** Vitreous deposits. AN = autonomic neuropathy; $C T S=$ carpal tunnel syndrome; $L M=$ leptomeningeal; PN = peripheral neuropathy 
Renal involvement can lead to proteinuria and end-stage renal disease requiring replacement therapy ${ }^{62}$ and TTR-FAP patients have been shown to display inappropriately low serum levels of erythropoietin and anaemia.6.

Over the years, progression of amyloid neuropathy and visceral organ involvement is paralleled by significant body weight loss, eventually leading to cachexia. Death occurs on average within 10 years of clinical onset. ${ }^{7,50,51,64}$

\section{Pathology and Pathophysiology}

Amyloid deposits, which can be unambiguously detected based on their pathognomonic green birefringence when stained with congo red and analysed under polarised light, start around endoneurial capillaries and slowly progress. The process is accompanied by degeneration of Schwann cells, destruction of unmyelinated fibres and in late stages, distortion of nerve fibres, demyelination and distal axonal degeneration. ${ }^{51}$ The mechanisms underlying the toxic effect of TTR amyloid formation are poorly understood. Mechanical effects, as well as a direct toxic insult from intermediates of the amyloidogenic process, could coincide to drive the neurodegeneration observed in TTR-FAP patients. ${ }^{65-69}$ Among Val30Met TTR-FAP patients, the composition of amyloid deposits seems to have some phenotypic and prognostic implications. Presence of TTR fragments in addition to full-length TTR within amyloid deposits is associated with later clinical onset and cardiac involvement. ${ }^{70}$ Moreover, patients having both fragmented and intact TTR molecules within the amyloid deposits are more likely to deteriorate pre-existing cardiomyopathy and heart failure after liver transplantation. ${ }^{71}$

\section{Diagnosis}

Physical examination and electrophysiological tests should point towards a form of length-dependent small-fibre sensorimotor polyneuropathy. ${ }^{51}$

In patients with no family history of neuropathy - not an uncommon occurrence in TTR-FAP due to the late onset and the low penetrance of TTR mutations in some areas ${ }^{51}$ - a nerve biopsy may be required to differentiate amyloid polyneuropathy from other conditions, such as chronic inflammatory demyelinating polyneuropathy (CIDP)..$^{51,72,73}$ In these cases, demonstration of amyloid deposits within the nerve allows diagnosis of an amyloid polyneuropathy. However, to possibly spare such an invasive procedure, abdominal fat aspiration, even if associated with a lower sensitivity compared with amyloid light-chain (AL) amyloidosis, should be performed early in the diagnostic work-up when amyloidosis is suspected, together with a search for mutations in TTR by means of direct sequencing. The demonstration of an amyloidogenic variant in the gene is mandatory for the ultimate diagnosis of this disease. Due to its significant allelic heterogeneity, sequencing of the entire coding regions of the TTR gene is always recommended.

A differential diagnosis among the various forms of amyloidosis associated with peripheral nerve involvement - that is, immunoglobulin AL amyloidosis and FAP with mutation in apolipoprotein $\mathrm{A}-\mathrm{I}$ or gelsolin - may be required in some cases. ${ }^{74}$

The demonstration of a monoclonal component in a patient with amyloid neuropathy is compatible with a diagnosis of AL amyloidosis requiring aggressive chemotherapy against the causal plasma cell clone. ${ }^{75}$ However, the possibility of an incidental association of a non-AL
Figure 1: Current and Emerging Therapies Against Transthyretin Amyloidosis

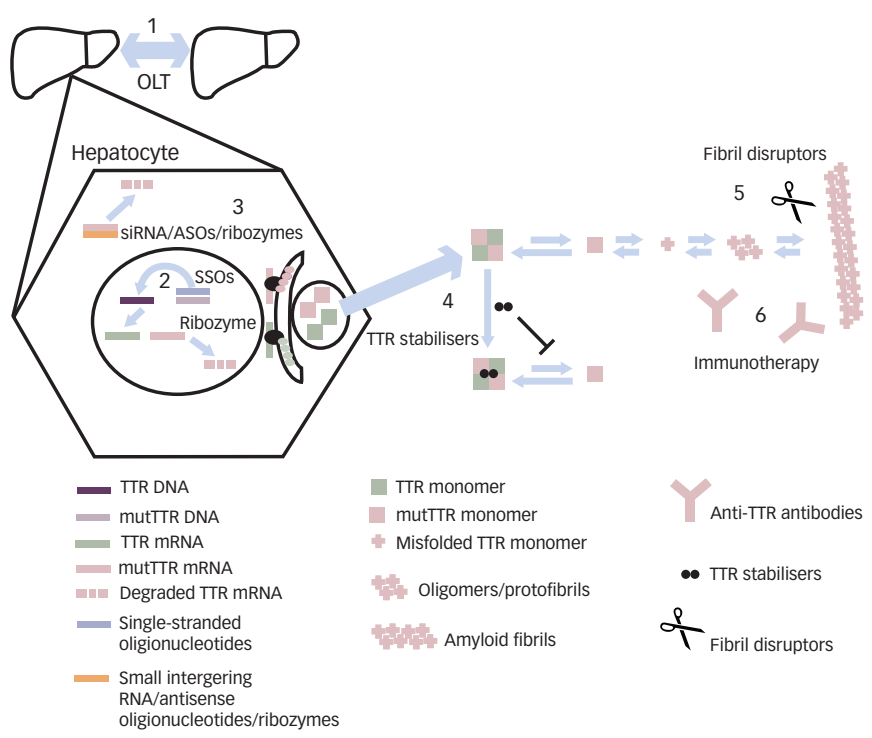

1: Orthotopic liver transplantation from cadaveric or living donors replaces the main site of transthyretin (TTR) production; 2: Targeted gene repair based on single-stranded oligonucleotides can convert the mutated TTR gene into the wild-type counterpart; 3: Ribozymes, small interfering RNA and antisense oligonucleotides can be used to downregulate the production of the disease-associated TTR; 4: Stabilisers of TTR tetramers, including diflunisal and tafamidis, can prevent their dissociation into monomers, therefore interfering with the rate-limiting step of TTR amyloidogenesis; 5: Disruptors of amyloid fibrils, including 4'-iodo-4'-deoxydoxorubicin and doxycycline, can favour the disaggregation and removal of amyloid fibrils; 6: Antibodies against misfolded TTR, TTR fibrils or serum amyloid $P$ can prevent amyloid formation and/or favour its removal. $A S O=$ antisense oligonucleotide; mRNA = messenger RNA; mutTR = mutated transthyretin; $O L T=$ orthotopic liver transplantation; siRNA = small interfering RNA; SSO = single-stranded oligonucleotide; TTR = transthyretin

systemic amyloidosis and an unrelated monoclonal gammopathy (more often a monoclonal gammopathy of undetermined significance [MGUS] ${ }^{76}$ should be taken into account. ${ }^{77,78}$ In these cases, unambiguous typing of the amyloid deposits with immuno-electron microscopy ${ }^{79}$ or mass spectrometry-based techniques ${ }^{80-82}$ and DNA testing is decisive.

FAP associated with mutations of apolipoprotein A-I (Gly26Arg, also termed lowa type) is rare and is generally accompanied by extra-neurological involvement including renal, hepatic and gastrointestinal involvement. ${ }^{83}$ If ATTR and AL amyloidosis have been excluded as causes of a biopsy-proven amyloid polyneuropathy, apolipoprotein A-I Gly26Arg is the most likely candidate to be considered. On the other hand, the epidemiological and clinical peculiarities of the remaining type of FAP render it unlikely to be considered in the differential diagnosis of an amyloid-associated sensorimotor polyneuropathy. Indeed, the form associated with mutations of gelsolin (also called FAP of Finnish type) is extremely rare, is present almost exclusively in Finland and typically presents with corneal lattice dystrophy followed by cranial neuropathy and cutis laxa. ${ }^{84}$

Alternatively, in the presence of a family history of TTR-FAP and a clear clinical picture, DNA testing is often sufficient to achieve a diagnosis. ${ }^{51}$ However, the possibility of alternative aetiologies (CIDP, AL amyloidosis) should be formally considered.

Finally, once a diagnosis of TTR-FAP has been achieved, careful extra-neurological investigations, including ophthalmological, cardiological and nephrological assessment, should be performed to determine the level of systemic involvement. Patients and family members are also to be offered adequate genetic counselling. 


\section{Treatment - Current and Prospective Therapies}

An intensive and multidisciplinary approach - including neurological, cardiological, ophthalmological, nutritional, nephrological and rehabilitative interventions - is required to alleviate the symptoms of TTR-FAP patients and to prevent complications associated with disease. ${ }^{51,85}$

However, aetiological treatments are needed to interfere with the cascade of events leading from TTR production to amyloidogenesis and organ dysfunction (see Figure 1).

\section{Reduction of the Amyloidogenic Precursor - Liver Transplantation} Akin to other types of systemic amyloidosis, the most effective way to achieve this goal is to eradicate or minimise the synthesis of the amyloidogenic precursor. This was attempted for the first time in 1990 through liver transplantation. ${ }^{86}$ Since then, more than 1,900 liver transplantation procedures have been performed, both from cadaveric and living donors (FAP World Transplant Registry, as of 31 December 2010, see www.fapwtr.org). Liver transplantation in TTR-FAP patients results in a sustained and significant reduction in plasma levels of mutated TTR ${ }^{87-89}$ and leads to increased survival. ${ }^{64,90}$ Non-Val30Met genotypes, a clinical onset after 50 years of age and an advanced clinical stage at the time of surgery adversely influence the outcome of liver transplantation. ${ }^{64,91}$ Therefore liver transplantation should ideally be performed in TTR-FAP patients at an early stage of the disease. On the other hand, pre-emptive liver transplantation in individuals at genetic risk of the disease is not feasible due to the incomplete penetrance of pathogenic TTR mutations. ${ }^{51}$

Following liver transplantation, visceral amyloid deposits can slowly regress, as documented by whole-body scintigraphy using radiolabelled SAP. ${ }^{92}$ More often, amyloid neuropathy does not significantly improve, but its progression can be halted. ${ }^{93}$ Liver transplantation does not generally impact the progression or de novo appearance of amyloid deposition in the eye or in the CNS, probably due to the unaffected local production of mutated TTR in the retina and in the choroid plexus. ${ }^{94-96}$ In the former case, pan-retinal laser photocoagulation aimed at destroying the TTR-producing retinal pigment epithelium could represent a valid therapeutic option, ${ }^{97}$ but further investigations are needed.

Remarkably, cardiac amyloidosis also progresses despite almost complete removal of variant TTR from the circulation with liver transplantation, most probably due to the continuous deposition of wild-type TTR in the myocardium. 18,19 The same mechanism could explain the progression of amyloid neuropathy occasionally seen in TTR-FAP patients who underwent liver transplantation, ${ }^{20}$ but in these cases the participation of mutated TTR synthesised by the choroid plexus and released in the endoneurial space via the subarachnoid space ${ }^{98}$ should be considered. In highly selected patients with severe involvement of the heart or kidney, a combined heart and liver or kidney and liver transplantation is a valid therapeutic option.99,100

Explanted livers of TTR-FAP patients, which are typically amyloid-free and do not show any abnormality other than producing a mutated TTR, can be used for so-called 'domino' liver transplantations, which, however, entail the risk of transmitting ATTR to the final recipient. ${ }^{101,102}$ Due to the shortage of liver donors, the requirement for life-long immunosuppressive regimens in recipients, the slight effect on ocular and cerebral deposits and the unfeasibility of liver transplantation for asymptomatic mutation carriers, other therapeutic approaches are urgently needed to halt the production of mutant TTR. ${ }^{103}$

\section{Targeted Gene Repair}

The possibility of correcting a pathogenic mutation in the mammalian genome by RNA/DNA oligonucleotides ${ }^{104}$ has encouraged researchers to apply this approach in order to repair a mutated TTR allele. As a proof of principle, a human hepatic cell line (HepG2) has been used to convert the endogenous wild-type TTR gene into the gene encoding the Val30Met mutant of TTR. ${ }^{105}$ Single-stranded oligonucleotides (SSOS) proved more efficient than chimeraplasts in achieving the desired gene conversion in vitro. ${ }^{106}$ The same approach was then applied to transgenic mice expressing murine TTR Val30Met. Intrahepatic, but not intraperitoneal, injection of SSOs led to a gene conversion of 8-9 \% at both messenger RNA (mRNA) and protein level. ${ }^{107}$

This strategy requires further methodological development ${ }^{103}$ and the capacity to target extrahepatic sites of TTR production needs to be assessed. Moreover, as observed with liver transplantation, this approach will not halt the progression of amyloid brought about by wild-type TTR if started after disease onset.

However, targeted gene repair could find invaluable applications in the treatment of asymptomatic carriers, especially in areas with high penetrance of pathogenic mutations, provided that safe and efficient protocols for gene conversion can be developed.

\section{Suppression of Mutant Transthyretin Messenger Ribonucleic Acid}

Earlier attempts at gene knockdown therapy in ATTR have aimed at achieving specific downregulation of mutant TTR mRNA, without altering the expression of wild-type TTR mRNA. Catalytically active RNAs termed hammerhead ribozymes allowed a significant reduction in wild-type or Val30Met TTR at mRNA and protein levels, in a cell-free system or in cell lines, to be achieved, using different constructs for the normal and mutated TTR. ${ }^{106,107}$ Also, hammerhead and hairpin ribozymes designed against another pathogenic TTR mutation, Glu61Lys, resulted in a significant reduction in mutant - but not wild-type - TTR (both mRNA and protein) in cell lines..$^{108}$ Likewise, small interfering RNA (SiRNA) was shown to downregulate Val30Met, but not wild-type, TTR mRNA and protein expression, even in cell lines expressing both alleles. ${ }^{109}$

Compared with targeted gene repair, which aims at correcting the genetic defect at the genomic level and can, therefore, be permanent, the above-mentioned gene knockdown technologies are transient and rely on continuous administration of the knockdown agent. A Phase I study for evaluating the toxicity profile, best schedule and effect on plasma TTR concentration of siRNA targeting TTR mRNA has been performed. The results were reported at the recent Eighth International Symposium on Familial Amyloidotic Polyneuropathy held 20-22 November 2011 at Kumamoto, Japan. Data presented at that time were from 31 patients (eight received placebo and 23 received drug) and showed that administration of ALN-TTR01 resulted in statistically significant reductions in serum TTR protein levels in ATTR patients. Lowering of serum TTR protein was found to be dose-dependent, rapid and durable after just a single dose. ${ }^{110}$

Alternative knockdown strategies based on the use of antisense oligonucleotides (ASOS) have been developed which aim at silencing both variant and normal TTR. The basis for this strategy relies on 
the fact that both variant and normal TTR are found in the deposits of TTR-FAP patients and, on the other hand, that TTR expression is dispensable, since TTR-null mice are viable, fertile and do not show any obvious phenotype apart from depressed levels of plasma retinol and thyroid hormone.111

Subcutaneous injection of anti-TTR ASOs in transgenic mice homozygous for human lle84Ser TTR and expressing high levels of the variant TTR resulted in a significant reduction in hepatic TTR mRNA and in circulating levels of TTR. ${ }^{112}$ This reduction in TTR levels could be protracted for up to six weeks by repeated applications of ASOs and was not accompanied by significant hepatotoxicity. ${ }^{112}$ No reduction in TTR levels could be observed in the choroid plexus, unless anti-TTR ASOs were administered locally via intracerebral ventricular injection. ${ }^{11}$ Studies are currently on-going to assess the safety of anti-TTR ASOs in non-human primates. ${ }^{114}$

\section{Immunisation}

Based on the enthusiasm accompanying the development of amyloid- $\beta$ (A $\beta$ ) immunotherapy against Alzheimer's disease, ${ }^{115}$ an active immunisation approach has been tested as a potentia treatment of ATTR in a preclinical model. Previous work had identified a TTR variant - TTR Tyr78Phe - which exposes a cryptic epitope present only on highly amyloidogenic TTR variants or on amyloid fibrils. ${ }^{116}$ Immunisation of transgenic mice expressing human Val30Met TTR $^{117}$ with TTR Tyr78Phe reduced or inhibited the formation of non-fibrillary and amyloid TTR as opposed to vehicle-treated or TTR Val30Met-immunised mice. ${ }^{118}$ In TTR Tyr78Phe-treated animals, common sites of TTR deposition were characterised by the presence of an inflammatory infiltrate composed mainly of B lymphocytes and macrophages, whereas no histological modifications were observed at TTR-synthesising sites. ${ }^{118}$ These results are encouraging, but further investigations are needed to extend these observations and develop a safe and effective immunotherapy against ATTR.

\section{Anti-serum Amyloid P Component Therapy}

Another strategy to interfere with the formation and persistence of amyloid deposits is directed against SAP. This is based on the observation that SAP prevents proteolysis of amyloid fibrils ${ }^{119}$ and accelerates their formation in vitro. ${ }^{120}$ A palindromic compound, (R)-1-[6-[(R)-2-carboxy-pyrrolidin-1-yl]-6-oxo-hexanoyl]pyrrolidine-2carboxylic acid (CPHPC) has been developed which inhibits SAP binding to amyloid fibrils, dramatically depletes circulating SAP and eventually removes SAP from amyloid deposits. ${ }^{121}$ The safety and biochemical and clinical effects of CPHPC in systemic amyloidoses have been investigated in a recent open-label proof-of-principle study. ${ }^{122}$ Overall, the drug appeared to be safe, but amyloid deposits persisted in most patients. The observation that residual SAP was still present in amyloid-laden tissues despite long-term treatment with CPHPC, and might therefore account for the persistence of amyloid deposits in the study subjects, formed the rationale for an integrative approach. Using an experimental mouse model of amyloidosis, the same group has investigated the effect of a combination of CPHPC treatment with the administration of a specific anti-SAP antibody. ${ }^{123}$ Mice treated with CPHPC and receiving a single injection of anti-SAP antibody showed a rapid complement-dependent, macrophage-derived giant-cell reaction, which resulted in a striking reduction in amyloid load when compared with untreated animals or animals receiving CPHPC alone. ${ }^{123} \mathrm{~A}$ fully humanised version of an anti-SAP monoclonal antibody is currently under investigation.

\section{Fibril Disruptors}

In 1995, we serendipitously discovered the anthracycline 4'-iodo-4'deoxydoxorubicin (IDOX) as the prototype of a class of compounds able to inhibit protein aggregation in vitro, in animal models of systemic amyloidosis ${ }^{124}$ and in patients. ${ }^{125,126}$ The first study showed that IDOX presented high affinity for all types of amyloid deposits and would have been a candidate for the treatment of all types of amyloidosis. ${ }^{124}$ It was demonstrated that IDOX was capable of inducing the destructuration of TTR amyloid fibrils. ${ }^{127}$ In consideration of the cytotoxicity of IDOX, in the following years the tetracycline antibiotics were investigated on the basis of structural homologies with the aglycone moiety of the anthracyclines. Doxycycline was able to interfere with TTR Leu55Pro amyloid formation and to disrupt TTR fibrils. ${ }^{128}$ Cardoso and Saraiva assessed the activity of doxycycline in vivo in the transgenic mouse model of ATTR and showed that the administration of doxycycline in drinking water resulted in the complete prevention of amyloid deposit formation. ${ }^{129}$ More recently, it has been reported that tauroursodeoxycholic acid (TUDCA), a biliary acid, administered to the same transgenic mouse model was effective at lowering deposited non-fibrillar TTR, as well as the levels of markers associated with pre-fibrillar TTR, but only at young ages. Combined cyclic doxycycline and TUDCA administration to mice with amyloid deposition was more effective than either doxycycline or TUDCA individually in significantly lowering TTR deposition and associated tissue markers. ${ }^{130}$ The observed synergistic effect of doxycycline plus TUDCA, in the range of quantities tolerable in humans, in the TTR transgenic mice models prompted their application in FAP, particularly in the early stages of disease. Based on these data, a Phase II clinical trial assessing the safety, efficacy and pharmacokinetics of doxycycline plus TUDCA in ATTR was designed and implemented at our institution in Pavia (NCT01171859 http://clinicaltrials.gov). The preliminary results were reported at the recent Eighth International Symposium on Familial Amyloidotic Polyneuropathy. ${ }^{131}$ In the 20 patients treated, no serious adverse events were registered. No clinical progression of cardiac involvement was observed. The neuropathy (Neuropathy Impairment Score in the Lower Limbs [NIS-LL] and Kumamoto score) remained substantially stable over one year. These preliminary data indicate that the combination of doxycycline and TUDCA stabilises the disease for at least one year in the majority of patients with an acceptable toxicity profile. ${ }^{131}$

\section{Stabilisation of Transthyretin Tetramers}

The discovery that TTR tetramer dissociation is the required first step in the amyloidogenic cascade has opened the avenue to the discovery of TTR kinetic stabilisers, acting like pharmacological chaperones which halt the amyloid process by preventing tetramer dissociation. ${ }^{15,132}$ Although numerous structurally distinct TTR kinetic stabilisers have been identified, 132 only two drugs, diflunisal (NCT00294671) and tafamidis meglumine (NCT01435655) have entered clinical trials. The results of the double-blind placebo-controlled diflunisal trial are not yet available; preliminary data indicate that the drug is well tolerated. ${ }^{133}$ The efficacy and safety of tafamidis (20 mg orally administered once daily) were evaluated in an 18-month randomised double-blind placebo-controlled trial involving 128 patients with TTR-FAP with the Val30Met mutation and primarily stage I disease. After 18 months of treatment, neuropathy did not progress in $60 \%$ of patients who received tafamidis meglumine versus $38 \%$ of the placebo group. Neurological deterioration was decreased by $52 \%$; quality of life and modified body mass index were maintained under tafamidis meglumine and worsened under placebo. ${ }^{134}$ Of the 91 patients completing the 18-month treatment period, 86 were subsequently enrolled in an 
open-label extension study, in which they all received once-daily $20 \mathrm{mg}$ tafamidis for a further 12 months. The rate of change in the NIS-LL score during the 12 months of treatment in this study was similar to that observed in those patients who had been randomised and treated with tafamidis in the previous double-blind 18-month period. ${ }^{134}$

In November 2011, tafamidis (Vyndaqel ${ }^{\circledR}$, Pfizer) was granted marketing authorisation by the European Commission for the treatment of ATTR in adult patients with stage I symptomatic polyneuropathy to delay peripheral neurological impairment. The availability of a pharmacological treatment for TTR-FAP is a milestone in the field of FAPS.

\section{Treatment Strategy}

A multidisciplinary approach to treatment of symptoms such as neuropathic pain, orthostatic hypotension, gastrointestinal malfunction, cardiac arrhythmias, cardiac failure, renal insufficiency and ocular disturbances remains fundamental. In all patients (carrying the Val30Met mutation or other mutations) diagnosed at stage I of the disease, the choice now is between early liver transplantation and tafamidis. Liver transplantation seems to reduce the rate of progression of the neuropathy but does not protect against cardiac involvement, which occurs in about $80 \%$ of cases of TTR-FAP. Cardiac and ocular amyloid depositions progress in patients who have undergone transplants, ${ }^{135}$ but whether these manifestations will be controlled by tafamidis remains to be seen. Patients with early disease manifestation should be put on a liver transplant waiting list and tafamidis may be started with mandatory periodic (every six months) evaluation. The patient may stay continuously on tafamidis unless early signs of disease progression should appear. In this case, liver transplantation should be promptly carried out. These indications are subject to modification as more data on the long-term effects of tafamidis treatment are gathered through the on-going post-marketing evaluation. As the data on the efficacy of diflunisal and doxycycline plus TUDCA mature, more treatment options might become available that will certainly affect treatment strategies.

\section{Concluding Remarks}

TTR-FAP has experienced revolutionary progress in our understanding of the mechanisms of this disease, which has translated into an unprecedented blooming of novel medicines. In the near future, the exploitation of these remedies is likely to deeply affect patient outcomes, with the grounded hope of making the invasive liver transplantation procedure no longer necessary. The availability of effective therapies will render the need for early diagnosis even more acute, as the amyloidoses are progressive, devastating diseases. We know now that it is very difficult to recover a damaged nervous system or heart; time is life. For this reason, the role of the neurologist remains fundamental: maintaining a high level of alert towards this rare, but potentially treatable, disease, will allow the timely identification of patients and the prompt institution of therapy.
1. Merlini G, Bellotti V, Molecular mechanisms of amyloidosis, N Engl J Med, 2003;349:583-96.

2. Sipe JD, Benson MD, Buxbaum JN, et al., Amyloid fibril protein nomenclature: 2010 recommendations from the nomenclature committee of the International society of nomenclature committee of the Internatosis, Amyloid, 2010;17:101-4.

3. Sethi S, Theis JD, Shiller SM, et al., Medullary amyloidosis associated with apolipoprotein A-IV deposition, Kidney Int, 2012;81:201-6.

4. Westermark P, Sletten K, Johansson B, Cornwell GG 3rd, Fibr in senile systemic amyloidosis is derived from normal transthyretin, Proc Natl Acad Sci U S A, 1990;87:2843-5.

5. Tanskanen M, Peuralinna T, Polvikoski T, et al., Senile systemic amyloidosis affects $25 \%$ of the very aged and associates with genetic variation in alpha2-macroglobulin and tau: a population-based autopsy study, Ann Med, and tau: a popu

. Saraiva MJ, Hereditary transthyretin amyloidosis: molecular basis and therapeutical strategies, Expert Rev Mol Med, 2002;4:1-11.

Benson MD, Kincaid JC, The molecular biology and clinical features of amyloid neuropathy, Muscle Nerve, 2007;36:411-23.

8. Jacobson DR, Pan T, Kyle RA, Buxbaum JN, Transthyretin ILE20, a new variant associated with late-onset cardiac amyloidosis, Hum Mutat, 1997:9:83-5.

9. Kyle RA, Gertz MA, Linke RP, Amyloid localized to tenosynovium at carpal tunnel release. Immunohistochemical identification of amyloid type, Am I Clin Pathol, 1992;97:250-3.

10. Sueyoshi T, Ueda M, Jono $H$, et al., Wild-type transthyretin-derived amyloidosis in various ligaments and tendons, Hum Pathol, 2011;42:1259-64.

11. Kanda Y, Goodman DS, Canfield RE, Morgan FJ, The amino acid sequence of human plasma prealbumin, J Biol Chem, 1974;249:6796-805.

12. Blake CC, Geisow MJ, Swan ID, et al., Structure of human plasma prealbumin at 2-5 A resolution. A preliminary report on the polypeptide chain conformation quaternary structure and thyroxine binding, J Mol Biol, 1974;88:1-12.

13. Vahlquist $A$, Peterson PA, Wibell $L$, Metabolism of the vitamin A transporting protein complex. I. Turnover studies in norma persons and in patients with chronic renal failure, Eur I Clin Invest, 1973;3:352-62.

14. Liu K, Cho HS, Lashuel HA, et al., A glimpse of a possible amyloidogenic intermediate of transthyretin, Nat Struct Biol, 2000:7:754-7.

15. Sekijima Y, Kelly JW, Ikeda S, Pathogenesis of and therapeutic strategies to ameliorate the transthyretin amyloidoses, Curr Pharm Des, 2008;14:3219-30.

16. Almeida MR, Alves IL, Terazaki H, et al., Comparative studies of two transthyretin variants with protective effects on familial amyloidotic polyneuropathy: TTR R104H and TTR T119M, Biochem Biophys Res Commun, 2000:270:1024-8.

17. Hammarstrom P, Schneider F, Kelly JW, Trans-suppression of misfolding in an amyloid disease, Science, 2001;293:2459-62.

18. Yazaki M, Tokuda T, Nakamura A, et al., Cardiac amyloid in patients with familial amyloid polyneuropathy consists of abundant wild-type transthyretin, Biochem Biophys Res Commun 2000;274:702-6.

19. Tsuchiya A, Yazaki M, Kametani F, et al., Marked regression of abdominal fat amyloid in patients with familial amyloid polyneuropathy during long-term follow-up after liver transplantation, Liver Transpl, 2008;14:563-70.

20. Liepnieks JJ, Zhang LQ, Benson MD, Progression of transthyretin amyloid neuropathy after liver transplantation, Neurology, 2010;75:324-7.

21. Ihse $E$, Suhr $O B$, Hellman $U$, Westermark $P$, Variation in amount of wild-type transthyretin in different fibril and tissue types in ATTR amyloidosis, I Mol Med, 2011:89:171-80

22. Thylen $\mathrm{C}$, Wahlqvist J, Haettner $\mathrm{E}$, et al., Modifications of transthyretin in amyloid fibrils: analysis of amyloid from homozygous and heterozygous individuals with the Met30 mutation, EMBO J, 1993;12:743-8.

23. Gustavsson A, Jahr H, Tobiassen R, et al., Amyloid fibril composition and transthyretin gene structure in senile systemic amyloidosis, Lab Invest, 1995;73:703-8.

24. Bergstrom J, Gustavsson A, Hellman U, et al., Amyloid deposits in transthyretin-derived amyloidosis: cleaved deposits in transthyretin-derived amyloidosis: cleaved
transthyretin is associated with distinct amyloid morphology J Pathol, 2005;206:224-32.

25. Benson MD, The hereditary amyloidoses, Best Pract Res Clin Rheumatol, 2003;17:909-27.

26. Andrade C, A peculiar form of peripheral neuropathy; familiar atypical generalized amyloidosis with special involvement of the peripheral nerves, Brain, 1952;75:408-27.

27. Araki S, Mawatari S, Ohta M, et al., Polyneuritic amyloidosis in a Japanese family, Arch Neurol, 1968:18:593-602.

28. Andersson R, Familial amyloidosis with polyneuropathy. A clinical study based on patients living in northern Sweden, Acta Med Scand Suppl, 1976;590:1-64.

29. Alves IL, Altland K, Almeida MR, et al., screening and biochemical characterization of transthyretin variants in the Portuguese population, Hum Mutat, 1997;9:226-33.

30. Araki S, Type I familial amyloidotic polyneuropathy (Japanese type), Brain Dev, 1984;6:128-33.

31. Munar-Ques M, Saraiva MJ, Viader-Farre C, et al., Genetic epidemiology of familial amyloid polyneuropathy in the Balearic Islands (Spain), Amyloid, 2005:12:54-61.

32. Reilly MM, Adams $D$, Booth $D R$, et al., Transthyretin gene analysis in European patients with suspected familial amyloid polyneuropathy, Brain, 1995;118(Pt 4):849-56.

33. Plante-Bordeneuve V, Lalu T, Misrahi M, et al., Genotypic phenotypic variations in a series of 65 patients with familia amyloid polyneuropathy, Neurology, 1998;51:708-14.

34. Hellman U, Alarcon F, Lundgren HE, et al., Heterogeneity of penetrance in familial amyloid polyneuropathy, ATTR Val30Met, in the Swedish population, Amyloid,
2008;15:181-6

35. Plante-Bordeneuve V, Carayol J, Ferreira A, et al., Genetic study of transthyretin amyloid neuropathies: carrier risks among French and Portuguese families, J Med Genet, 2003;40:e120

36. Bonaiti B, Alarcon F, Bonaiti-Pellie C, Plante-Bordeneuve V, Parent-of-origin effect in transthyretin related amyloid polyneuropathy, Amyloid, 2009;16:149-50

37. Drugge $U$, Andersson R, Chizari F, et al., Familial amyloidotic polyneuropathy in Sweden: a pedigree analysis, I Med Genet, 1993;30:388-92

38. Sousa A, Coelho T, Barros J, Sequeiros J, Genetic epidemiology of familial amyloidotic polyneuropathy (FAP)-type I in Povoa do Varzim and Vila do Conde (north of Portugal), Am J Med Genet, 1995;60:512-21.

39. Yamamoto K, Ikeda S, Hanyu N, et al., A pedigree analysis with minimised ascertainment bias shows anticipation in Met30-transthyretin related familial amyloid polyneuropathy, I Med Genet, 1998;35:23-30.

40. Soares ML, Coelho T, Sousa A, et al., Haplotypes and DNA sequence variation within and surrounding the transthyretin gene: genotype-phenotype correlations in familial amyloid polyneuropathy (V30M) in Portugal and Sweden, Eur I Hum Genet, 2004;12:225-37.

41. Soares ML, Coelho T, Sousa A, et al., susceptibility and modifier genes in Portuguese transthyretin V30M amyloid polyneuropathy: complexity in a single-gene disease, Hum Mol Genet, 2005; 14:543-53

42. Dardiotis E, Koutsou P, Zamba-Papanicolaou E, et al, Complement $\mathrm{C} 1 \mathrm{Q}$ polymorphisms modulate onset in familial amyloidotic polyneuropathy TTR Val30Met, J Neurol Sci, 2009;284:158-62.

43. Bonaiti B, Olsson M, Hellman U, et al., TTR familial amyloid polyneuropathy: does a mitochondrial polymorphism entirely explain the parent-of-origin difference in penetrance?, Eur I Hum Genet, 2010;18:948-52.

44. Olsson M, Norgren N, Obayashi K, et al., A possible role for miRNA silencing in disease phenotype variation in Swedish transthyretin V30M carriers, BMC Med Genet, 2010;11:130.

45. Sack GH Jr, Dumars KW, Gummerson KS, et al., Three forms of dominant amyloid neuropathy, Johns Hopkins Med 1981;149:239-47.

46. Munar-Ques M, Pedrosa JL, Coelho T, et al., Two pairs of proven monozygotic twins discordant for familial amyloid neuropathy (FAP) TTR Met 30, J Med Genet, 1999;36:629-32.

47. Ando $\mathrm{Y}$, Ohtsu $\mathrm{Y}$, Terazaki $\mathrm{H}$, et al., Japanese monozygotic twins with familial amyloidotic polyneuropathy (FAP) (ATTR Val30Met), Amyloid, 2000;7:133-6.

48. Holmgren $\mathrm{G}$, Wikstrom $\mathrm{L}$, Lundgren $\mathrm{HE}$, Suhr $\mathrm{OB}$, Discordant penetrance of the trait for familial amyloidotic polyneuropathy in two pairs of monozygotic twins, J Intern Med, 2004;256:453-6.

49. Saporta MA, Plante-Bordeneuve V, Misrahi M, Cruz MW, 
Discordant expression of familial amyloid polyneuropathy in monozygotic Brazlilan twins, Amyloid, 2009;16:38-41.

50. Araki S, Ando Y, Transthyretin-related familial amyloidotic polyneuropathy-Progress in Kumamoto, Japan (1967-2010) Proc Jpn Acad Ser B Phys Biol Sci, 2010;86:694-706.

51. Plante-Bordeneuve V, Said G, Familial amyloid polyneuropathy, Lancet Neurol, 2011:10:1086-97.

52. Lessell S, Wolf PA, Benson MD, Cohen AS, Scalloped pupils in familial amyloidosis, N Engl J Med, 1975;293:914-5.

53. Brett M, Persey MR, Reilly MM, et al., Transthyretin Leu12Pro is associated with systemic, neuropathic and leptomeningea amyloidosis, Brain, 1999;122(Pt 2):183-90.

54. Uitti RJ, Donat JR, Rozdilsky B, et al., Familial oculoleptomeningeal amyloidosis. Report of a new family with unusual features, Arch Neurol, 1988;45:1118-22.

55. Uemichi T, Uitti RJ, Koeppen AH, et al., Oculoleptomeningea amyloidosis associated with a new transthyretin variant Ser64, Arch Neurol, 1999:56:1152-5.

56. Revesz T, Holton JL, Lashley T, et al., Genetics and molecular pathogenesis of sporadic and hereditary cerebral amyloid angiopathies, Acta Neuropathol, 2009;118:115-30.

57. Suhr OB, Anan I, Backman C, et al., Do troponin and B-natriuretic peptide detect cardiomyopathy in transthyretin amyloidosis? I Intern Med, 2008;263:294-301.

58. Rapezzi C, Merlini G, Quarta CC, et al., Systemic cardiac amyloidoses: disease profiles and clinical courses of the 3 main types, Circulation, 2009:120:1203-12.

59. Rapezzi C, Quarta CC, Riva L, et al., Transthyretin-related amyloidoses and the heart: a clinical overview, Nat Rev Cardiol, 2010;7:398-408.

60. Janunger T, Anan I, Holmgren G, et al., Heart failure caused by a novel amyloidogenic mutation of the transthyretin gene: ATTR Ala45Ser, Amyloid, 2000;7:137-40.

61. Ando $E$, Ando $Y$, Okamura $R$, et al., Ocular manifestations of familial amyloidotic polyneuropathy type I: Iong-term follow up, Br I Ophthalmol, 1997:81:295-8.

62. Lobato L, Beirao I, Silva M, et al., End-stage renal disease and dialysis in hereditary amyloidosis TTR V3OM presentation, survival and prognostic factors, Amyloid, 2004;11:27-37.

63. Beirao I, Lobato L, Costa PM, et al., Kidney and anemia in familial amyloidosis type I, Kidney Int, 2004;66:2004-9.

64. Yamashita $\mathrm{T}$, Ando $\mathrm{Y}$, Okamoto $\mathrm{S}$, et al., Long-term survival after liver transplantation in patients with familial amyloid polyneuropathy, Neurology, 2012;78:637-43.

65. Sousa MM, Cardoso I, Fernandes R, et al., Deposition of transthyretin in early stages of familial amyloidotic polyneuropathy: evidence for toxicity of nonfibrillar aggregates, Am J Pathol, 2001;159:1993-2000.

66. Sousa MM, Saraiva MJ, Neurodegeneration in familial amyloid polyneuropathy: from pathology to molecular signaling, Prog Neurobiol, 2003;71:385-400

67. Reixach $\mathrm{N}$, Deechongkit $\mathrm{S}$, Jiang $\mathrm{X}$, et al., Tissue damage in the amyloidoses: Transthyretin monomers and nonnative oligomers are the major cytotoxic species in tissue culture, Proc Natl Acad Sci U S A, 2004:101:2817-22.

68. Pepys MB, Amyloidosis, Annu Rev Med, 2006:57:223-41.

69. Hou X, Aguilar MI, Small DH, Transthyretin and familial amyloidotic polyneuropathy. Recent progress in understanding the molecular mechanism of neurodegeneration, FEBS I, 2007;274:1637-50.

70. Inse $E$, Ybo A, Suhr $\mathrm{O}$, et al., Amyloid fibril composition is related to the phenotype of hereditary transthyretin V30M amyloidosis, J Pathol, 2008;216:253-61.

71. Gustafsson S, Ihse E, Henein MY et al., Amyloid fibril composition as a predictor of development of cardiomyopathy after liver transplantation for hereditary transthyretin amyloidosis, Transplantation, 2012; [Epub ahead of print].

72. Koike $\mathrm{H}$, Hashimoto $\mathrm{R}$, Tomita M, et al., Diagnosis of sporadic transthyretin Val30Met familial amyloid polyneuropathy: practical analysis, Amyloid, 2011;18:53-62

73. Mathis S, Magy L, Diallo L, et al., Amyloid neuropathy mimicking chronic inflammatory demyelinating polyneuropathy, Muscle Nerve, 2012;45:26-31.

74. Anesi E, Palladini G, Perfetti V, et al., Therapeutic advances demand accurate typing of amyloid deposits, Am J Med, 2001:111:243-4.

75. Merlini G, Seldin DC, Gertz MA, Amyloidosis: pathogenesis and new therapeutic options, J Clin Oncol, 2011:29:1924-33.

76. Kyle RA, Rajkumar SV, Epidemiology of the plasma-cell disorders, Best Pract Res Clin Haematol, 2007;20:637-64.

7. Lachmann HJ, Booth DR, Booth SE, et al., Misdiagnosis of hereditary amyloidosis as AL (primary) amyloidosis, N Engl J Med, 2002;346:1786-91.

78. Cappellari M, Cavallaro T, Ferrarini $\mathrm{M}$, et al., Variable presentations of TTR-related familial amyloid polyneuropathy in seventeen patients, J Peripher Nerv Syst, 2011;16:119-29.

79 Arbustini $\mathrm{E}$, Verga $\mathrm{L}$, Concardi $\mathrm{M}$, et al., Electron and immuno-electron microscopy of abdominal fat identifies and characterizes amyloid fibrils in suspected cardiac amyloidosis, Amyloid, 2002;9:108-14.

80. Lavatelli F, Perlman DH, Spencer B, et al., Amyloidogenic an associated proteins in systemic amyloidosis proteome of adipose tissue, Mol Cell Proteomics, 2008;7:1570-83.

81. Valentini $V$, Lavatelli $F$, Obici L, et al., Proteomic characterization of amyloid deposits in transthyretin amyidosis associated with various mutations, Amyloid, 2011;18(Suppl. 1):56-8.

82. Klein CJ, Vrana JA, Theis JD, et al., Mass spectrometric-based proteomic analysis of amyloid neuropathy type in nerve tissue, Arch Neurol, 2011:68:195-9.

83. Nichols WC, Gregg RE, Brewer HB Jr, Benson MD, A mutation in apolipoprotein $A-1$ in the lowa type of familial amyloidotic polyneuropathy, Genomics, 1990;8:318-23.

84. Kiuru S, Gelsolin-related familial amyloidosis, Finnish type (FAF), and its variants found worldwide, Amyloid, 1998;5:55-66. 5. Adams D, Samuel D, Slama M, [Treatment of familial amylo polyneuropathy], Presse Med, 2012; [Epub ahead of print].

86. Holmgren G, Steen L, Ekstedt J, et al., Biochemical effect of liver transplantation in two Swedish patients with familial amyloidotic polyneuropathy (FAP-met30), Clin Genet, 1991;40:242-6.

87. Holmgren $\mathrm{G}$, Ericzon BG, Groth $\mathrm{CG}$, et al., Clinical improvement and amyloid regression after liver transplantation in hereditary transthyretin amyloidosis, Lancet, 1993;341:1113-6.

88. Ando $Y$, Tanaka $Y$, Ando $E$, et al., Effect of liver transplantation on autonomic dysfunction in familial amyloidotic polyneuropathy type I, Lancet, 1995;345:195-6.

89. Ribeiro-Silva C, Gilberto S, Gomes RA, et al., The relative amounts of plasma transthyretin forms in familial transthyretin amyloidosis: a quantitative analysis by Fourier transform ion-cyclotron resonance mass spectrometry, Amyloid, 2011:18:191-9.

90. Okamoto S, Wixner J, Obayashi K, et al., Liver transplantatio for familial amyloidotic polyneuropathy: impact on Swedish patients' survival, Liver Transpl, 2009;15:1229-35.

91. Herlenius G, Wilczek HE, Larsson M, Ericzon BG, Ten years of international experience with liver transplantation for familial amyloidotic polyneuropathy: results from the Familial Amyloidotic Polyneuropathy World Transplant Registry, Transplantation, 2004:77:64-71.

92. Rydh A, Suhr $O$, Hietala SO, et al.., Serum amyloid $P$ component scintigraphy in familial amyloid polyneuropathy: regression of visceral amyloid following liver transplantation Eur J Nucl Med, 1998;25:709-13.

93. Yamamoto S, Wilczek HE, Nowak G, et al., Liver transplantation for familial amyloidotic polyneuropathy (FAP): a single-center experience over 16 years, Am I Transplant, 2007;7:2597-604.

94. Ando $\mathrm{Y}$, Terazaki $\mathrm{H}$, Nakamura $\mathrm{M}$, et al., A different amyloid formation mechanism: de novo oculoleptomeningeal amyloid deposits after liver transplantation, Transplantation, 2004;77:345-9.

95. Sandgren $\mathrm{O}$, Kiellgren $\mathrm{D}$, Suhr $\mathrm{OB}$, Ocular manifestations in liver transplant recipients with familial amyloid polyneuropathy, Acta Ophthalmol, 2008;86:520-4.

96. Hara R, Kawaji T, Ando E, et al., Impact of liver transplantation on transthyretin-related ocular amyloidosis in Japanese patients, Arch Ophthalmol, 2010;128:206-10.

97. Kawaji T, Ando Y, Hara R, Tanihara H, Novel therapy for transthyretin-related ocular amyloidosis: a pilot study of retinal laser photocoagulation, Ophthalmology, 2010;117:552-5

98. Pettersson CA, Drainage of molecules from subarachnoid space to spinal nerve roots and peripheral nerve of the rat. A study based on Evans blue-albumin and lanthanum as tracers, Acta Neuropathol, 1993;86:636-44.

99. Pilato E, Dell'Amore A, Botta L, Arpesella G, Combined heart and liver transplantation for familial amyloidotic neuropathy, Eur I Cardiothorac Surg, 2007;32:180-2.

100. Lobato L, Beirao I, Seca R, et al., Combined liver-kidney transplantation in familial amyloidotic polyneuropathy TTR V30M: nephrological assessment, Amyloid, 2011:18(Suppl. 1):185-7.

101. Stangou AJ, Heaton ND, Hawkins PN, Transmission of systemic transthyretin amyloidosis by means of domino liver transplantation, N Eng/ J Med, 2005;352:2356.

102. Llado L, Baliellas C, Casasnovas C, et al., Risk of transmission of systemic transthyretin amyloidosis after domino liver transplantation, Liver Transpl, 2010;16:1386-92.

103. Nakamura $M$, Ando $Y$, Applications of gene therapy for familial amyloidotic polyneuropathy, Expert Opin Biol Ther 2004;4:1621-7.

104. Cole-Strauss A, Yoon K, Xiang Y, et al., Correction of the mutation responsible for sickle cell anemia by an RNA-DNA oligonucleotide, Science, 1996;273:1386-9.

105. Nakamura $\mathrm{M}$, Ando $\mathrm{Y}$, Nagahara S, et al., Targeted conversion of the transthyretin gene in vitro and in vivo, Gene Ther, 2004;11:838-46.

106. Propsting MJ, Blaschke M, Haas RE, et al., Inosine(15.1) hammerhead ribozymes for targeting the transthyretin-30 mutation, Biochem Biophys Res Commun, 1999;260:313-7.

107. Propsting MJ, Kubicka S, Genschel J, et al., Inhibition of transthyretin-met30 expression using Inosine(15.1)-Hammerhead ribozymes in cell culture, Biochem Biophys Res Commun, 2000;279:970-3.

108. Tanaka K, Yamada T, Ohyagi Y, et al., Suppression of transthyretin expression by ribozymes: a possible therapy for familial amyloidotic polyneuropathy, J Neurol Sci, 2001;183:79-84.

109. Kurosawa T, Igarashi S, Nishizawa M, Onodera O, Selective silencing of a mutant transthyretin allele by small interfering RNAs, Biochem Biophys Res Commun,

2005;337:1012-8

110. Coelho T, Suhr OB, Adams A, et al., Phase I safety, pharmacokinetic and pharmacodynamic results for ALN-TTR01, a novel RNAi therapeutic for the treatment of transthyretin amyloidosis. In: Ando Y (ed.), VIIlth International Symposium on Familial Amyloidotic Polyneuropathy, Kumamoto: Japan Intractable Diseases Research Foundation, 2011:62.

111. Episkopou V, Maeda S, Nishiguchi S, et al., Disruption of the transthyretin gene results in mice with depressed levels of plasma retinol and thyroid hormone, Proc Natl Acad Sci U S A 1993;90:2375-9

112. Benson MD, Kluve-Beckerman B, Zeldenrust SR, et al., Targeted suppression of an amyloidogenic transthyretin with antisense oligonucleotides, Muscle Nerve, 2006;33:609-18

113. Benson MD, Smith RA, Hung G, et al., Suppression of choroid plexus transthyretin levels by antisense oligonucleotide treatment, Amyloid, 2010;17:43-9.

114. Benson MD, Pandey S, Witchell D, et al., Antisense oligonucleotide therapy for TTR amyloidosis, Amyloid, 2011;18(Suppl. 1):55.

115. Schenk D, Barbour R, Dunn W, et al., Immunization with amyloid-beta attenuates Alzheimer-disease-like pathology in the PDAPP mouse, Nature, 1999;400:173-7.

116. Redondo C, Damas AM, Olofsson A, et al., Search for intermediate structures in transthyretin fibrillogenesis soluble tetrameric Tyr78Phe TTR expresses a specific epitope present only in amyloid fibrils, J Mol Biol, 2000;304:461-70.

117. Kohno K, Palha JA, Miyakawa K, et al., Analysis of amyloid deposition in a transgenic mouse model of homozygous familial amyloidotic polyneuropathy, Am J Pathol, 1997;150:1497-508.

118. Terazaki H, Ando Y, Fernandes R, et al., Immunization in familial amyloidotic polyneuropathy: counteracting deposition by immunization with a Y78F TTR mutant, Lab Invest, 2006:86:23-31.

119. Tennent GA, Lovat LB, Pepys MB, Serum amyloid P component prevents proteolysis of the amyloid fibrils of Alzheimer disease and systemic amyloidosis, Proc Natl Acad Sci U S A, 1995;92:4299-303.

120. Myers SL, Jones S, Jahn TR, et al., A systematic study of the effect of physiological factors on beta2-microglobulin amyloid formation at neutral $\mathrm{pH}$, Biochemistry, 2006;45:2311-21.

121. Pepys MB, Herbert J, Hutchinson WL, et al., Targeted pharmacological depletion of serum amyloid P component for treatment of human amyloidosis, Nature, 2002;417:254-9.

122. Gillmore JD, Tennent GA, Hutchinson WL, et al., sustained pharmacological depletion of serum amyloid $\mathrm{P}$ component in patients with systemic amyloidosis, Br J Haematol, 2010;148:760-7.

123. Bodin K, Ellmerich S, Kahan MC, et al., Antibodies to huma serum amyloid $\mathrm{P}$ component eliminate visceral amyloid deposits, Nature, 2010;468:93-7.

124. Merlini G, Ascari E, Amboldi N, et al., Interaction of the anthracycline 4'-iodo-4'-deoxydoxorubicin with amyloid fibrils: inhibition of amyloidogenesis, Proc Natl Acad Sci U S A 1995;92:2959-63.

125. Gianni L, Bellotti V, Gianni AM, Merlini G, New drug therapy of amyloidoses: resorption of AL-type deposits with 4'-iodo-4'-deoxydoxorubicin, Blood, 1995;86:855-61.

126. Gertz MA, Lacy MQ, Dispenzieri A, et al., A multicenter phase II trial of 4 '-iodo-4' deoxydoxorubicin (IDOX) in primary amyloidosis (AL), Amyloid, 2002;9:24-30

127. Palha JA, Ballinari D, Amboldi N, et al., 4'-iodo-4'deoxydoxorubicin disrupts the fibrillar structure of transthyretin amyloid, Am J Pathol, 2000;156:1919-25.

128. Cardoso I, Merlini G, Saraiva MJ, 4'-iodo-4'-Deoxydoxorubicin and tetracyclines disrupt transthyretin amyloid fibrils in vitro producing noncytotoxic species: screening for TTR fibril disrupters, FASEB J. 2003:17:803-9.

129. Cardoso I, Saraiva MJ, Doxycycline disrupts transthyretin amyloid: evidence from studies in a FAP transgenic mice model, FASEB J, 2006;20:234-9.

130. Cardoso I, Martins D, Ribeiro T, et al., Synergy of combined doxycycline/TUDCA treatment in lowering transthyretin deposition and associated biomarkers: studies in FAP mouse models, I Trans/ Med, 2010:8:74

131. Merlini G, Obici L, Cortese A, Saraiva MJ, Doxycycline plus tauroursodeoxycholic acid for transthyretin amyloidosis: a phase II study. In: Ando Y (ed.), VIIIth International Symposium on Familial Amyloidotic Polyneuropathy, Kumamoto: Japan Intractable Diseases Research Foundation, 2011;58

132. Johnson SM, Connelly S, Fearns C, et al., The transthyretin amyloidoses: from delineating the molecular mechanism of aggregation linked to pathology to a regulatory-agencyapproved drug, I Mol Biol, 2012; [Epub ahead of print].

133. Berk JL, Dyck PJ, Obici L, et al., The diflunisal trial: update on study drug tolerance and disease progression, Amyloid, 2011:18(Suppl. 1):191-2.

134. Assessment report Vyndaqel tafamidis meglumine, EMAEEPA. Available at: www.ema.europa.eu/docs/en_GB/document_ library/EPAR__Product_Information/human/002294/ WC500117862.pdf (accessed 12 March 2012).

135. Ohya Y, Okamoto S, Tasaki M, et al., Manifestations of transthyretin-related familial amyloidotic polyneuropathy: Long-term follow-up of Japanese patients after liver 